\title{
Biological Therapy in Noninfectious Pediatric Uveitis: A Systematic Review
}

\author{
Luiz Fernando Norcia (D) \\ Olívia Pereira Kiappe iD ${ }^{2}$ \\ Eliane Chaves Jorge (iD ${ }^{2}$ \\ 'Botucatu Medical School, São Paulo \\ State University (UNESP), Botucatu, São \\ Paulo, Brazil; ${ }^{2}$ Department of Surgical \\ Specialties and Anesthesiology \\ (Ophthalmology Division), Botucatu \\ Medical School, São Paulo State \\ University (UNESP), Botucatu, São Paulo, \\ Brazil
}

Purpose: Noninfectious pediatric uveitis is a potentially blinding disease often associated with systemic conditions. In cases of chronic anterior uveitis without adequate response to steroids and immunosuppressants, biological response modifiers would be viable therapeutic options. Still, evidence is lacking on the safety of the long-term use of these drugs in children. Therefore, this study aimed to evaluate the efficacy and safety of biological therapy to treat noninfectious pediatric uveitis.

Methods: A systematic review was performed to identify original studies involving biological therapy for children diagnosed with noninfectious uveitis. Quality of evidence was assessed using the Grading of Recommendations, Assessment, Development, and Evaluation (GRADE) classification system.

Results: Nine studies involving 526 children were eligible. Adalimumab was superior to placebo in reducing inflammatory activity (risk ratio (RR) 3.21 [95\% confidence interval (CI) 1.65-6.27]; $\mathrm{P}=0.0006 ; \mathrm{I}^{2}=0 \%$ ) and steroid use (RR 2.27 [95\% CI 1.03-4.99]; $\mathrm{P}=0.04 ; \mathrm{I}^{2}$ $=0 \%$, low-certainty evidence). There was no difference between adalimumab and placebo in the occurrence of systemic adverse events (RR 2.51 [95\% CI 0.74-8.54]; P = 0.14; $\mathrm{I}^{2}=48 \%$ ) and local events (RR 1.15 [95\% CI 0.46-2.88]; P=0.76; $\mathrm{I}^{2}=1 \%$ ). There was no difference between adalimumab and infliximab in response to treatment (RR 1.18 [95\% CI 0.69-2.03]; $\mathrm{P}=0.55 ; \mathrm{I}^{2}=91 \%$, very low-certainty evidence) and in the occurrence of adverse effects (RR 0.84 [95\% CI $0.41-1.73] ; \mathrm{P}=0.64 ; \mathrm{I}^{2}=18 \%$, low-certainty evidence).

Conclusion: There is low to very-low evidence that biological therapy is effective and safe in managing noninfectious pediatric uveitis. Future large randomized trials may provide more substantial evidence to confirm these results.

Keywords: uveitis, children, biological therapy, systematic review

\section{Introduction}

Uveitis is an inflammatory disorder of the uveal tract that can result in vision loss and blindness. ${ }^{1}$ It is rarer in children than in adults, accounting for $2-20 \%$ of all cases worldwide. ${ }^{2}$ Pediatric uveitis is a topic of particular interest because of its diagnostic and therapeutic challenges. ${ }^{3}$ Children with uveitis are frequently asymptomatic; however, the ocular inflammatory activity is commonly anterior, bilateral, chronic, recurrent, and resistant to conventional treatment, increasing the risk of vision-threatening complications. ${ }^{3,4}$ Noninfectious cases account for $69-95 \%$ of total pediatric uveitis cases, with juvenile idiopathic arthritis being the most frequent etiology. ${ }^{5,6}$

A step-wise treatment for pediatric noninfectious uveitis is essential to maintain inflammatory control and decrease the risk of the potential local and systemic side
Correspondence: Eliane Chaves Jorge Department of Surgical Specialties and Anesthesiology, São Paulo State

University (UNESP), Medical School, Ave.

Professor Mário Rubens Guimarães

Montenegro s/n, Botucatu, 18618-687,

São Paulo, Brazil

Email eliane.jorge@unesp.br 
effects of drugs. A typical approach begins with topical and oral steroids, with the addition of other therapies, as needed. $^{7}$

Systemic disease-modifying antirheumatic drug (DMARD) therapy is used early in cases of resistance to treatment or steroid dependence. ${ }^{3,4}$ The conventional DMARD of choice continues to be methotrexate (MTX). ${ }^{4}$ Biological therapies, such as adalimumab (TNF- $\alpha$ inhibitor) and other biologic DMARDs, have emerged as therapeutic alternatives but only as second options. ${ }^{4,7}$ Studies have reported the efficacy of biological therapy, especially anti-TNF- $\alpha$ agents, in chronic nonin-

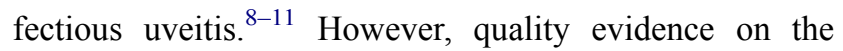
safety of regular use of these drugs in children is lacking. ${ }^{9,10}$ Therefore, we performed an updated systematic review of the literature to assess the clinical efficacy of biological therapy in treating noninfectious pediatric uveitis.

\section{Methods}

This systematic review was developed according to the guidelines of the Cochrane Handbook for Systematic Intervention Reviews ${ }^{12}$ and described according to Preferred Reporting Items for Systematic Reviews and Meta-Analyses (PRISMA) recommendations. ${ }^{13}$

\section{Eligibility Criteria}

Randomized controlled trials (RCTs) and nonrandomized controlled studies (NRS) involving children under 18 years old with noninfectious uveitis, regardless of sex and type of associated systemic disease, were included. Interventions included any treatment regimen of biological therapy versus placebo, other drugs, or a combination of therapies. The primary outcome was the rate of satisfactory response to treatment, characterized by the reduction or resolution of ocular inflammatory activity in the anterior chamber and the occurrence of local and systemic adverse events. The secondary outcome included reduction in or interruption of the use of corticosteroids.

\section{Data Source and Searches}

Seven databases were searched in this review, including the Cochrane Central Register of Controlled Trials (CENTRAL; 1996 to March 2021), PubMed (1966 to March 2021), Web of Science (1900 to March 2021), EMBASE (1974 to March 2021), Latin American and Caribbean Literature in Health Sciences (LILACS; 1982 to March 2021), SCOPUS (2004 to March 2021), and
Clinical Trials (2008 to March 2021). Using the terms of the Medical Subject Headings (MeSH) and accessible terms related to "uveitis," "tumor necrosis factor antagonist alpha," and "child," the search strategy was adapted and replicated for each database. There were no restrictions on language or publication year.

The proposed search strategy was as follows: [(uveitis or iritis or iridocyclitis or pars planitis or retinochoroiditis or choroiditis or retinitis or Behcet or Vogt or Koyanagi or Harada or Fuchs or juvenile rheumatoid or juvenile idiopathic arthritis) and ((Tumor necrosis factor-alpha) or biologic therapy or biological therapies monoclonal antibodies or humanized monoclonal antibodies or Infliximab or Adalimumab or Etanercept or Certolizumab Pegol or Remicade or Humira or Enbrel or Golimumab or Simponi or Cimzia or (TNFR-Fc fusion protein)) and (child or children or pediatric or pediatrics or childhood) and (noninfectious)].

\section{Study Selection and Data Extraction}

Two authors independently screened the search results using research titles and, when available, abstracts. Then, according to pre-specified selection criteria, the full texts of the selected articles were retrieved and independently assessed for inclusion by two reviewers. Disagreement was resolved through consensus and consultation with a third author in case of any dissent.

The data from the included studies were independently extracted by two reviewers using a standard data extraction form with the following information: Study characteristics (design, methods of randomization), participants, interventions, and outcomes (types of outcome measures, adverse events).

\section{Risk of Bias Assessment}

The quality of RCTs was assessed using the "risk of bias" tool in Cochrane Collaboration, ${ }^{12}$ which followed these criteria: Random sequence generation, allocation concealment, masking of participants and researchers, masking of outcome assessment, incomplete outcome data, selective outcome reporting, and other sources of bias. For the analysis of NRS, the reviewers used another tool developed by Cochrane Collaboration, ${ }^{14}$ the "risk of bias in non-randomized studies of interventions" (ROBINS-I), which covers seven domains: Confusion, selection of participants, measurement of intervention, non-receipt of assigned intervention, losses, measurement of outcomes, and selective reporting of outcomes. When information 
regarding the risk of bias or related to other aspects of the methodology was not available or clear, the reviewers tried to contact the authors of the studies to clarify doubts and obtain additional information. Two reviewers independently assessed the risk of bias in the included studies, and any disagreement was resolved through discussion or consensus involving all authors.

\section{Certainty of Evidence}

The GRADE methodology was adopted to determine the degree of certainty of evidence ${ }^{15,16}$ using five criteria: Global risk of bias, inaccuracy, inconsistency, indirect evidence, and publication bias. The degree of certainty for each result analyzed was classified as high, moderate, low, or very low. The results were summarized in an evidence profile. The reviewers lowered the degree of certainty of the evidence according to the influence of the assessment criteria. ${ }^{15,17}$

\section{Data Synthesis and Statistical Analysis}

All outcomes were analyzed using dichotomous variables, combined Mantel-Haenszel RRs, and associated 95\% confidence interval (CI) using random-effects models to data from three or more studies. The analyses were based on eligible patients who had reported outcomes in each study. Review Manager 5.3.5 (RevMan) software ${ }^{18}$ was used to perform all analyses. The variability of the results was estimated from the $\mathrm{I}^{2}$ statistic and the p-value for the heterogeneity chi-square test. Heterogeneity was considered significant when $\mathrm{I}^{2}>75 \%$. $^{12}$

\section{Results}

\section{Study Selection}

Figure 1 shows the process of identifying eligible studies. A total of 2384 citations were identified after removing duplicates. Through the screening based on titles and abstracts, 132 studies were found relevant to the subject. After full-text analysis, 34 were assessed for possible eligibility, of which 25 were excluded and 9 were included in the review consisting of 3 RCTs (Smith 2005, Quartier 2017 and Ramanan 2017) ${ }^{19-21}$ and 6 non-randomized studies (Tynjälä 2007, Simonini 2011, Zannin 2013, Gaidar 2014, Cecchin 2018, and Gunduz 2021), ${ }^{22-27}$ with a total of 526 participants included.

\section{Study Characteristics}

Table 1 describes the characteristics of the included studies, such as design, country, number of centers involved, length of follow-up, number of participants, age, sex, intervention, and control. Three studies were conducted in Italy, ${ }^{23,24,26}$ one in France, ${ }^{20}$ one in the United Kingdom, ${ }^{21}$ one in Finland, ${ }^{22}$ one in Russia, ${ }^{25}$ one in Turkey, ${ }^{27}$ and one in the USA. ${ }^{19}$ Three studies were conducted in a single center, ${ }^{19,25,27}$ and the other six studies were multicentric. ${ }^{20-24,26}$ The sample size of the included studies ranged from $12^{19}$ to $154^{26}$ children. There was a predominance of females, and the average age ranged from $8.5^{21}$ to $15.2^{27}$ years. The follow-up of the studies ranged from three ${ }^{25}$ to fifty ${ }^{27}$ months.

Regarding the type of intervention adopted, seven studies used adalimumab (Humira ${ }^{\circledR}$, Abbott, Abbott Park, Green Oaks, IL, USA), ${ }^{20,21,23-27}$ and two studies used etanercept $\left(\right.$ Enbrel $^{\circledR}$, Pfizer, Pfizer Manufacturing Belgium NV, Puurs, ANR, Belgium). ${ }^{19,22}$ For the control group, six studies used infliximab (Remicade ${ }^{\circledR}$, Janssen, Janssen Biotech, Titusville, NJ, USA), ${ }^{22-27}$ and three used placebo. ${ }^{19-21}$ In the studies involving a placebo group, ${ }^{19-21}$ for ethical reasons, all the children continued to receive pharmacological therapy, mainly methotrexate and corticosteroids. No child remained untreated.

\section{Risk of Bias in the Included Studies}

Figures 2 and 3 present the risk of bias in the studies included in the review. For RCTs, the main issues related to risk of bias were lack of information about the random sequence generation, ${ }^{19}$ allocation concealment, ${ }^{20}$ masking of outcome assessment, ${ }^{19}$ and other biases (conflict of financial interest). ${ }^{20}$ For NRS, the main issues related to risk of bias were confounding factors and the selection process of participants. $^{22-27}$

\section{Intervention Effects}

\section{Anti-TNF $\alpha$ Agents versus Placebo}

Three RCTs compared anti-TNFa agents versus placebo: Smith (2005) (etanercept), Quartier (2017) (adalimumab), and Ramanan (2017) (adalimumab). ${ }^{19-21}$ For the primary outcomes, anti-TNF $\alpha$ agents improved the chances of a satisfactory response to treatment compared to placebo ((RR 2.57 [95\% CI 1.39-4.74]; P = 0.003; three studies; two drugs, $\mathrm{I}^{2}=4 \%$ ) (Figure 4) and (RR 3.21 [95\% CI 1.656.27]; $\mathrm{P}=0.0006$; two studies; one drug; $\mathrm{I}^{2}=0 \%$ (Figure 5)).

Two RCTs ${ }^{20,21}$ reported systemic severe adverse events with adalimumab; however, there was no difference compared to placebo (RR 2.51 [95\% CI 0.74-8.54]; P = 0.14; $\mathrm{I}^{2}=48 \%$ ). Regarding local adverse effects, there was also no difference between adalimumab and placebo (RR 1.15 [95\% CI 0.46-2.88]; $\mathrm{P}=0.76 ; \mathrm{I}^{2}=1 \%$ ). 


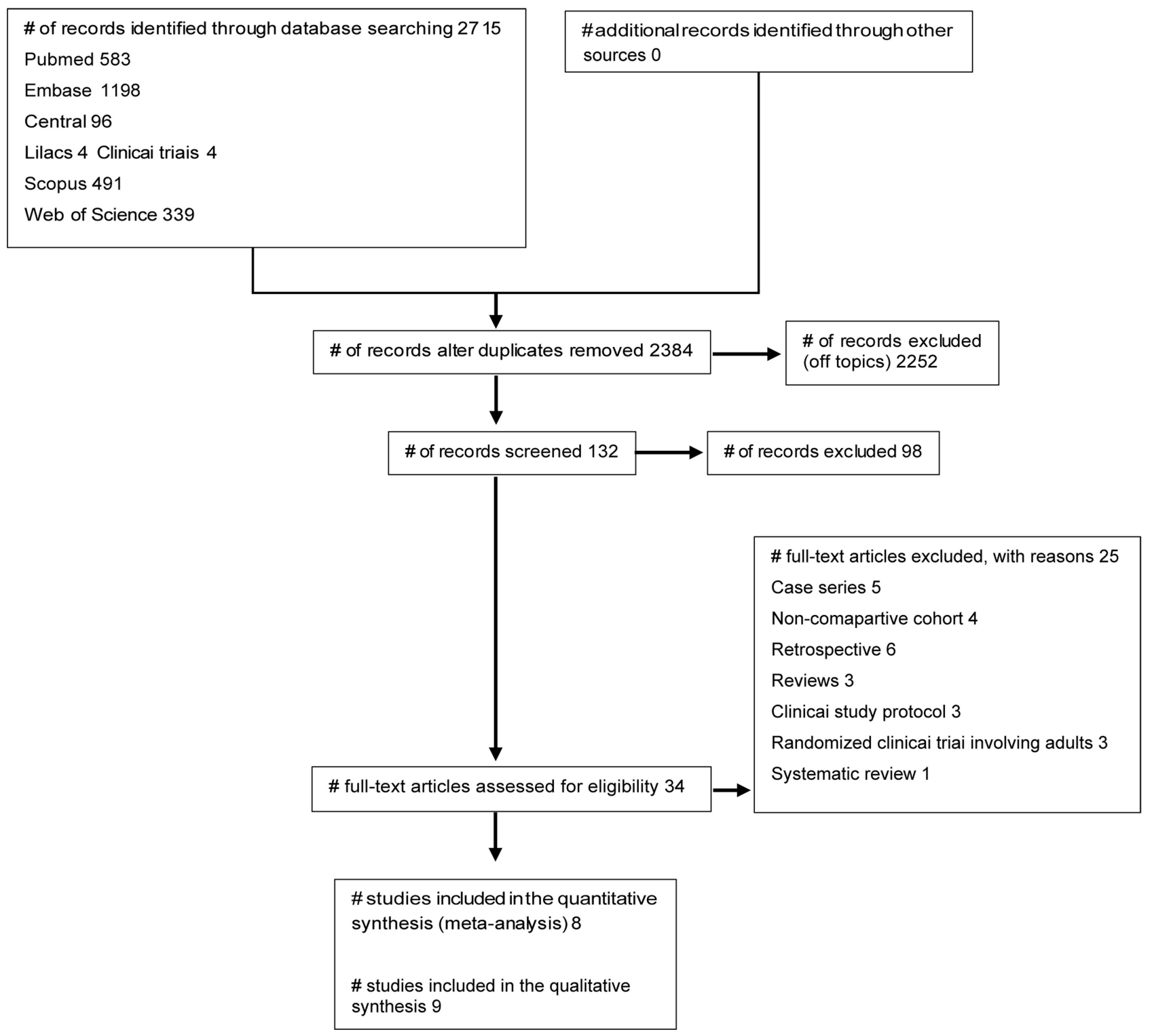

Figure I Review flowchart.

For the secondary outcome, adalimumab increased the chance of reducing or interrupting corticosteroid use compared to placebo (RR 2.27 [95\% CI 1.03-4.99]; $\mathrm{P}=0.04$; $\mathrm{I}^{2}=0$ ) (Figure 6).

\section{Adalimumab versus Infliximab}

Five NRS compared adalimumab and infliximab (Simonini 2011, ${ }^{23}$ Zannin 2012, ${ }^{24}$ Gaidar 2014, ${ }^{25}$ Cecchin 2018, ${ }^{26}$ and Gunduz $2021^{27}$ ). Regarding primary outcomes, the analysis evidenced no difference between the two anti-TNF- $\alpha$ agents concerning a satisfactory response to treatment (RR 1.18 [95\% CI 0.69-2.03]; $\mathrm{P}=0.55$, five studies; $\mathrm{I}^{2}=91 \%$ ) (Figure 7) and the occurrence of local and systemic adverse events
(RR 0.84 [95\% CI 0.41-1.73]; $\mathrm{P}=0.64$, four studies; $\mathrm{I}^{2}=18 \%$ ) (Figure 8).

No study reported a reduction in or interruption of corticosteroid use in this comparison.

Figures 9-Figure 13 summarize findings for the main comparisons according to the GRADE classification. The certainty of the evidence of the outcomes varied from very low to low quality.

\section{Discussion}

\section{Main Findings}

This review sought to address the uncertainties regarding biological therapy in children with noninfectious uveitis. 


\begin{tabular}{|c|c|c|c|c|c|c|c|c|c|}
\hline ڤั & 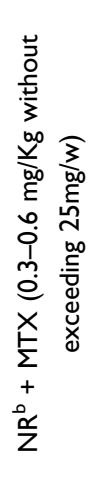 & 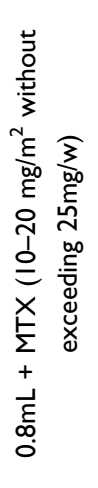 & 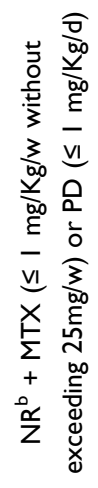 & $\begin{array}{l}\stackrel{0}{0} \\
\stackrel{0}{b 0} \\
\xi \\
n\end{array}$ & 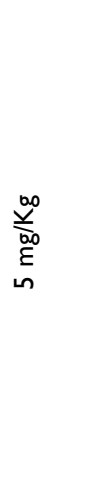 & 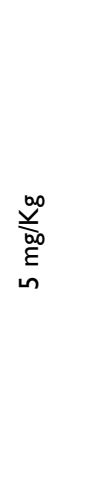 & 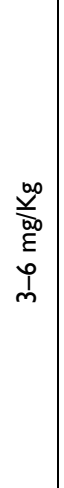 & 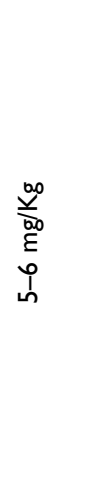 & 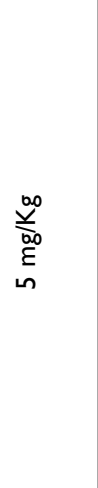 \\
\hline z & $\underline{\underline{n}}$ & ᄋ & เ & 品 & $\simeq$ & $\stackrel{\infty}{+}$ & $\bar{N}$ & $\sigma$ & $\underline{\varrho}$ \\
\hline 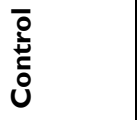 & $\begin{array}{l}\circ \\
\stackrel{\circ}{\underline{u}} \\
\frac{\tilde{\sigma}}{\alpha}\end{array}$ & $\begin{array}{l}\circ \\
\stackrel{\circ}{0} \\
\frac{\mathscr{J}}{\alpha}\end{array}$ & $\begin{array}{l}\circ \\
\stackrel{8}{0} \\
\frac{\sigma}{0} \\
\frac{\sigma}{\alpha}\end{array}$ & $\stackrel{x}{\underline{\underline{x}}}$ & 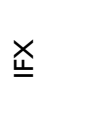 & 站 & 经 & 站 & 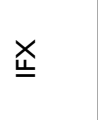 \\
\hline $\begin{array}{l}\text { ڤ̆ } \\
\text { ڤn }\end{array}$ & 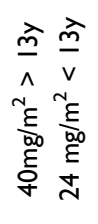 & 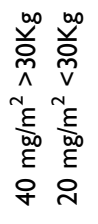 & $\begin{array}{l}\infty_{0}^{\infty} \\
\stackrel{0}{w_{0}} \\
\varepsilon \\
\vdots \\
0\end{array}$ & 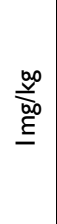 & 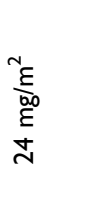 & 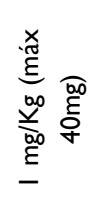 & $\begin{array}{l}\stackrel{\infty}{0} \\
\stackrel{0}{b 0} \\
\varepsilon \\
+ \\
0\end{array}$ & 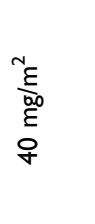 & 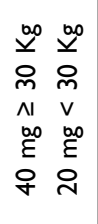 \\
\hline $\mathbf{z}$ & $\underline{\bullet}$ & ㅇ & $\wedge$ & 2 & $\underline{0}$ & $\stackrel{q}{q}$ & $\stackrel{ \pm}{\sim}$ & $\stackrel{\infty}{\sim}$ & $\simeq$ \\
\hline 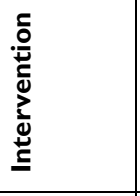 & 选 & 造 & $\underset{w}{E}$ & 案 & 选 & 选 & 芯 & 选 & 造 \\
\hline$\stackrel{x}{\tilde{\omega}} \bar{\uplus} \widehat{\Sigma}$ & 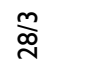 & হ ণ & $\frac{m}{\sigma}$ & $\stackrel{m}{ \pm}$ & $\bar{\lambda}=$ & $\gtreqless \circ$ & $\stackrel{\infty}{5}$ & 층 & $\underline{a} \pm$ \\
\hline 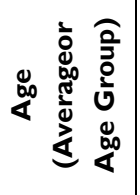 & 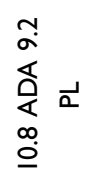 & 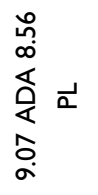 & $=$ & $\stackrel{\text { ำ }}{\alpha}$ & న & $\hat{\sigma}$ & $\stackrel{\infty}{\sigma}$ & $\frac{1}{1}$ & 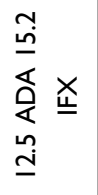 \\
\hline 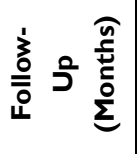 & $\simeq$ & $\stackrel{ \pm}{\sim}$ & $\simeq$ & 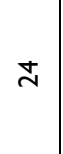 & $\underset{\text { I }}{\text { I }}$ & $\simeq$ & \pm & $\stackrel{\infty}{m_{m}^{*}}$ & 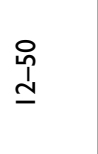 \\
\hline ฮֶّ & 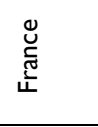 & 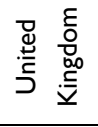 & 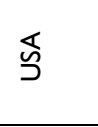 & 츹 & 츹 & 촢 & 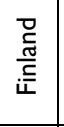 & 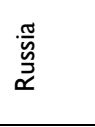 & 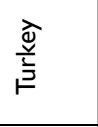 \\
\hline Uั & $\sigma$ & \pm & - & $\stackrel{ \pm}{\sim}$ & $m$ & $\stackrel{\infty}{z}$ & $m$ & - & - \\
\hline 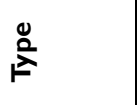 & $\stackrel{\leftarrow}{\check{x}}$ & $\underset{\Upsilon}{\longleftarrow}$ & $\stackrel{\leftarrow}{\check{x}}$ & $\begin{array}{l}a \\
\tilde{\omega} \\
\frac{\tilde{z}}{z}\end{array}$ & $\begin{array}{l}\text { a } \\
\tilde{u} \\
\text { 文 }\end{array}$ & $\begin{array}{l}\stackrel{a}{\tilde{n}} \\
\stackrel{u}{z}\end{array}$ & $\begin{array}{l}\frac{\alpha}{\omega} \\
\frac{u}{z}\end{array}$ & 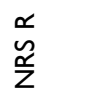 & $\begin{array}{l}\stackrel{\alpha}{ } \\
\widetilde{u} \\
\underline{z}\end{array}$ \\
\hline 氞 & 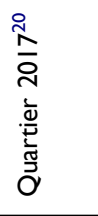 & 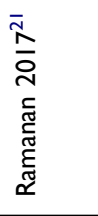 & 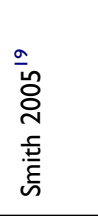 & 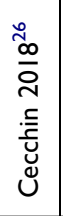 & 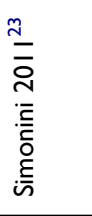 & 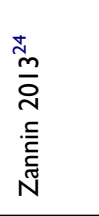 & 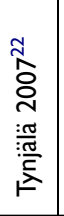 & 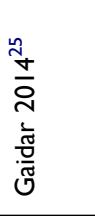 & 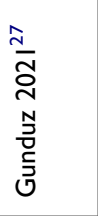 \\
\hline
\end{tabular}




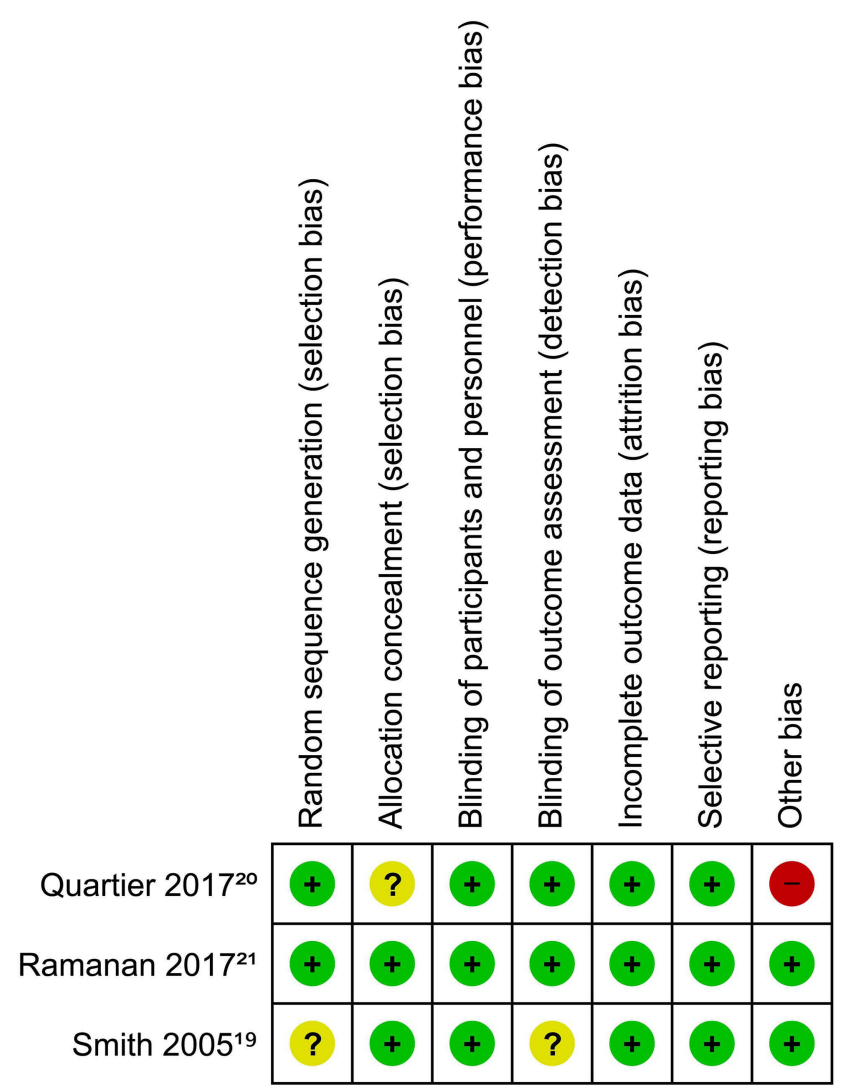

Figure 2 Summary of risk of bias from randomized clinical trials. Review the authors' judgments about each item of risk of bias for each study included in the meta-analysis.
Despite their high cost, these drugs, especially infliximab and adalimumab, represent a new strategy in the long-term control of the visual outcomes and ocular complications in refractory uveitis.

The meta-analysis demonstrated that anti-TNF $\alpha$ agents are more effective than placebo and maintained the corticosteroids or traditional DMARDs already used by children in reducing ocular inflammatory activity. Adalimumab in monotherapy improved the chances of a satisfactory response to treatment; however, it had similar effectiveness to infliximab. However, the benefits of etanercept cannot be evaluated because of methodological differences between the two included RCTs that used the drug. ${ }^{19,22}$

Regarding adverse events, the results suggested that adalimumab has a good long-term safety profile and can effectively reduce or interrupt corticosteroid therapy.

These results can help choose the best treatment logistics, improving clinical care for children with chronic and refractory noninfectious uveitis.

\section{Applicability and Quality of Evidence}

Regarding the applicability of evidence, the use of anti-TNF $-\alpha$ in clinical practice is still limited by high costs and restricted access. In the developing world, more affordable

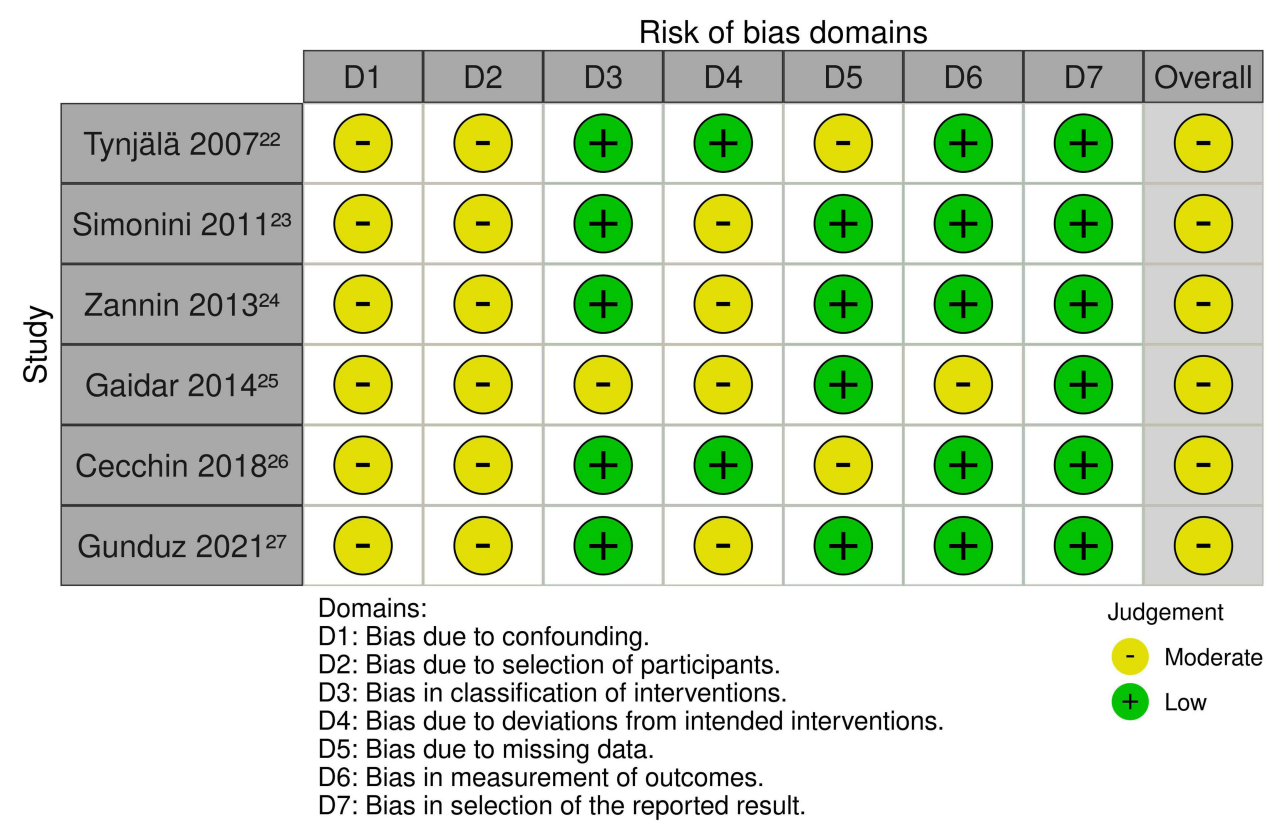

Figure 3 Summary of risk of bias from non-randomized controlled trials. 


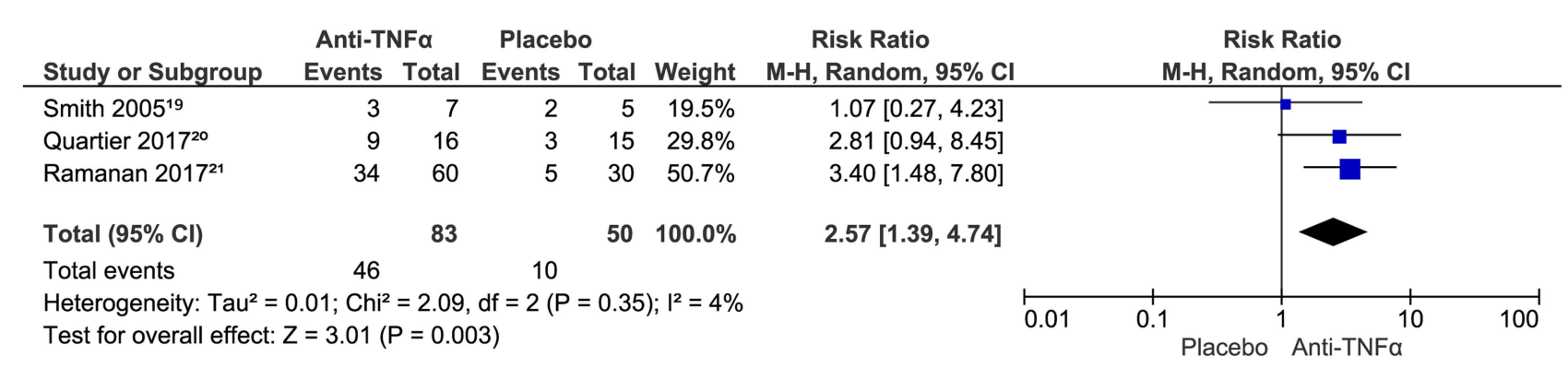

Figure 4 Comparison: Anti-TNF- $\alpha$ versus placebo. Outcome: Satisfactory response rate to treatment.

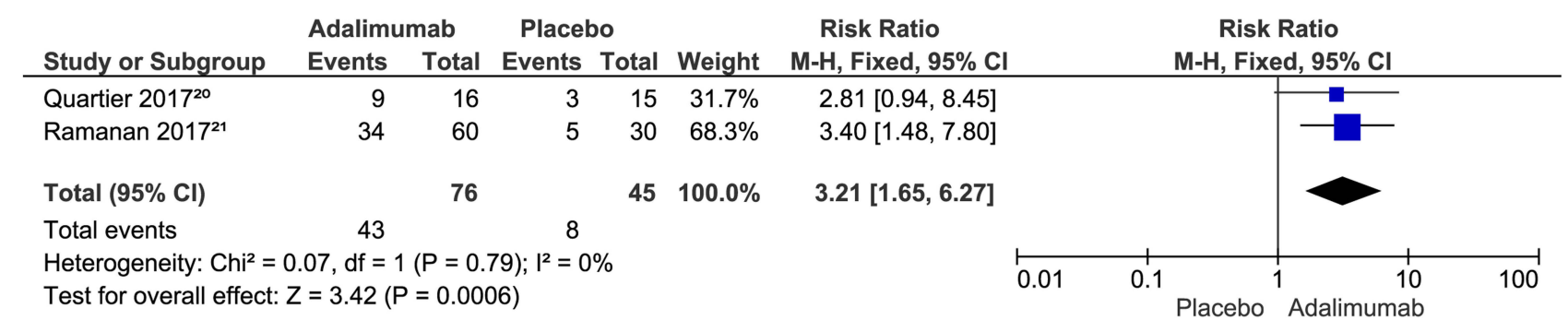

Figure 5 Comparison: Adalimumab versus placebo. Outcome: Satisfactory response rate to treatment.

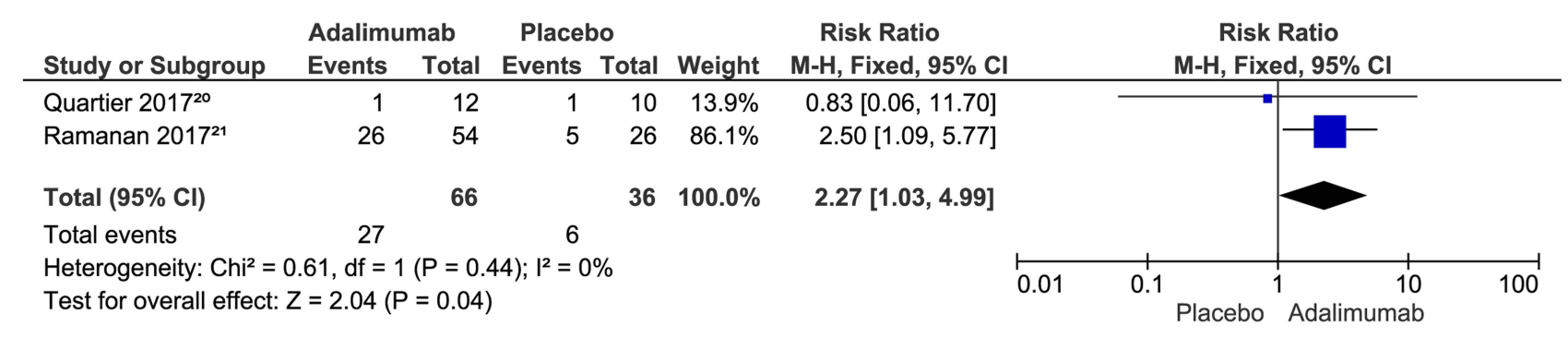

Figure 6 Comparison: Adalimumab versus placebo. Outcome: Reduction or interruption of the use of corticosteroids.

\begin{tabular}{|c|c|c|c|c|c|c|c|c|c|}
\hline \multirow[b]{2}{*}{ Study or Subgroup } & \multicolumn{2}{|c|}{ Adalimumab } & \multicolumn{2}{|c|}{ Infliximab } & \multirow[b]{2}{*}{ Weight } & \multicolumn{2}{|l|}{ Risk Ratio } & \multirow{2}{*}{$\begin{array}{c}\text { Risk Ratio } \\
\text { M-H, Random, } 95 \% \text { Cl }\end{array}$} & \\
\hline & Events & Total & Events & Total & & M-H, Random, $95 \% \mathrm{Cl}$ & & & \\
\hline Gunduz $2021^{27}$ & 10 & 17 & 14 & 16 & $19.7 \%$ & $0.67[0.43,1.04]$ & & & \\
\hline Gaidar $2014^{25}$ & 17 & 28 & 7 & 9 & $19.5 \%$ & $0.78[0.49,1.24]$ & & 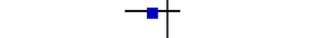 & \\
\hline Simonini $2011^{23}$ & 15 & 16 & 16 & 17 & $22.1 \%$ & $1.00[0.84,1.18]$ & & & \\
\hline Zannin $2013^{24}$ & 29 & 43 & 18 & 42 & $20.1 \%$ & $1.57[1.05,2.36]$ & & & \\
\hline Cecchin $2018^{26}$ & 57 & 95 & 12 & 59 & $18.6 \%$ & $2.95[1.73,5.02]$ & & & \\
\hline Total $(95 \% \mathrm{Cl})$ & & 199 & & 143 & $100.0 \%$ & $1.18[0.69,2.03]$ & & & \\
\hline Total events & 128 & & 67 & & & & & & \\
\hline $\begin{array}{l}\text { Heterogeneity: } \mathrm{Tau}^{2}= \\
\text { Test for overall effect: }\end{array}$ & $\begin{array}{l}.34 ; \mathrm{Chi}^{2} \\
=0.60(\mathrm{~F}\end{array}$ & $\begin{array}{l}42.74, \\
=0.55)\end{array}$ & $d f=4(P$ & $<0.00$ & $001) ;\left.\right|^{2}=$ & $1 \%$ & 0.01 & $\begin{array}{llr}0.1 & 1 & 10 \\
\text { Infliximab } & \text { Adalimumab }\end{array}$ & 100 \\
\hline
\end{tabular}

Figure 7 Comparison: Adalimumab versus infliximab. Outcome: Satisfactory response rate to treatment.

drugs such as corticosteroids ${ }^{28,29}$ and immunosuppressants ${ }^{30}$ are the most viable therapeutic options. In these countries, however, the cost-benefit discussion on adalimumab has divided opinions. Hughes et al reported that in the United Kingdom, adalimumab does not currently represent a cost- effective treatment option for the public health system. ${ }^{31}$ Other authors, however, opposed the conclusions of the study, contesting the methodology used and emphasizing the lack of therapeutic options in cases of resistance to methotrexate, with the same clinical efficacy as 


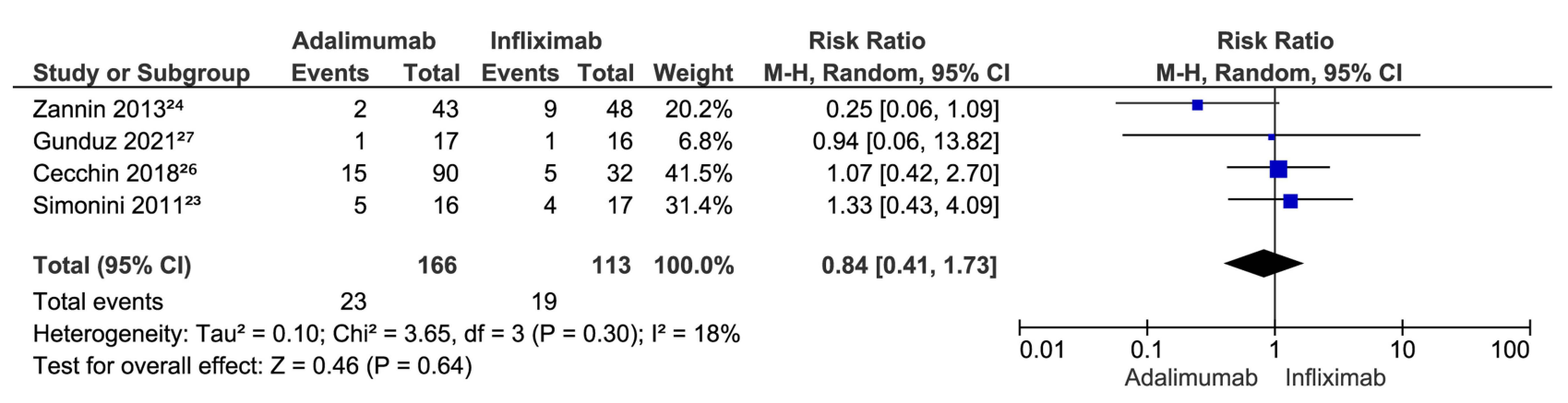

Figure 8 Comparison: Adalimumab versus infliximab. Outcome: occurrence of local and systemic adverse events.

Summary of findings:

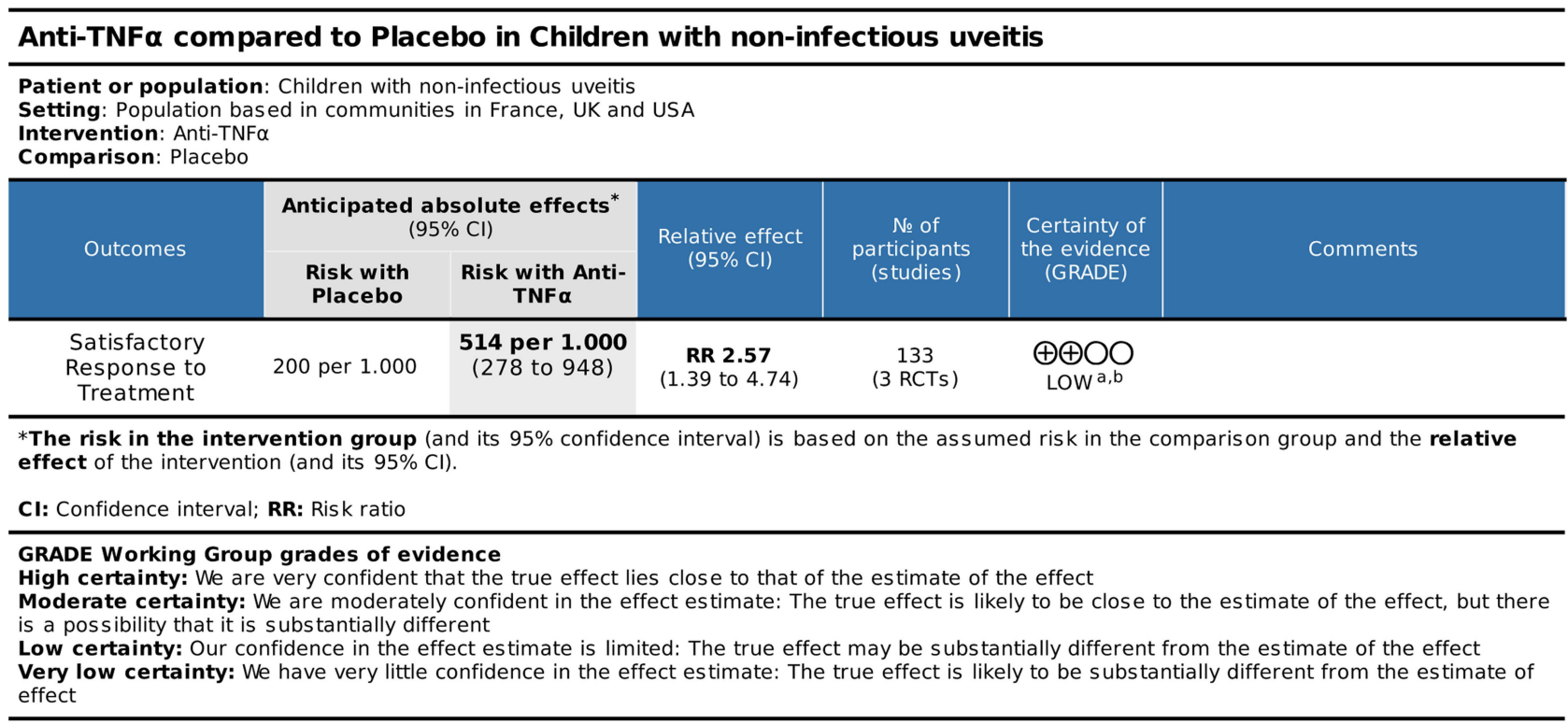

\section{Explanations}

a. Downgrade to imprecision because $\mathrm{Cl} 95 \%$ for absolute effects inclsuded clinically important benefit and no benefit. In addition, the sample size was small and did not reach $\mathrm{Cl} 95 \%$.

b. Downgrade to publication bias due to external financial benefit and relatively short follow-up period.

Figure 9 Summary of findings for the comparison of anti-TNF- $\alpha$ versus placebo. Outcome: Satisfactory response to treatment.

adalimumab. $^{32,33}$ In the present review, only one study (Ramanan $2017^{21}$ ) reported data on quality of life and the cost-effectiveness of treatment.

The evidence on the action of anti-TNF- $\alpha$ agents will be reinforced soon with the results of clinical trials in progress. We highlight the RCT (NCT03828019) in the recruitment stage, which aims to compare the clinical efficacy of adalimumab with that of conventional immunosuppressive therapy, which is expected to end in 2023.

The methodological quality of the included RCTs was, in general, classified as having a low risk of bias while that of NRS as having moderate risk. Quality of evidence, meanwhile, varied from very low to low; that is, confidence in the estimated effect is limited, and the actual effect may be substantially different from the estimated effect.

\section{Relation to Prior Work}

A systematic review that is relevant to our objectives was published in 2014. Simonini et $\mathrm{al}^{34}$ included 22 retrospective studies, and only one RCT was excluded in the analysis. Furthermore, the authors did not use the GRADE classification to assess the certainty of the evidence. The authors concluded that the results based on retrospective studies did not have the strength yet to change the level of recommendation of anti-TNF $\alpha$ agents for noninfectious uveitis in children. Therefore, with the results of this review, there is already evidence that supports the use of 
Summary of findings:

\begin{tabular}{|c|c|c|c|c|c|c|}
\hline Adalimumab & ipared to $P$ & cebo for Chil & Iren with nc & -infectiou & veitis & \\
\hline $\begin{array}{l}\text { Patient or popula } \\
\text { Setting: Population } \\
\text { Intervention: Adal } \\
\text { Comparison: Place }\end{array}$ & $\begin{array}{l}\text { : Children with } \\
\text { ed in communit } \\
\text { nab }\end{array}$ & $\begin{array}{l}\text { n-infectious uveitis } \\
\text { s in France and UK }\end{array}$ & & & & \\
\hline utrame & $\begin{array}{r}\text { Anticipated } \\
(9\end{array}$ & $\begin{array}{l}\text { solute effects } \\
\% \mathrm{Cl})\end{array}$ & Relative effect & № of & Certainty of & Commonts \\
\hline dicevitics & $\begin{array}{l}\text { Risk with } \\
\text { Placebo }\end{array}$ & $\begin{array}{c}\text { Risk with } \\
\text { Adalimumab }\end{array}$ & (95\% Cl & (studies) & (GRADE) & 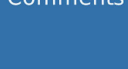 \\
\hline $\begin{array}{c}\text { Satisfactory } \\
\text { Response to } \\
\text { Treatment }\end{array}$ & 178 per 1.000 & $\begin{array}{l}\mathbf{5 7 1} \text { per } 1.000 \\
(293 \text { to } 1.000)\end{array}$ & $\begin{array}{c}\mathbf{R R} \mathbf{3 . 2 1} \\
\text { (1.65 to } 6.27)\end{array}$ & $\begin{array}{l}121 \\
\text { (2 RCTs) }\end{array}$ & $\underset{\text { LOW }^{a, b}}{\bigoplus}$ & \\
\hline
\end{tabular}

*The risk in the intervention group (and its $95 \%$ confidence interval) is based on the assumed risk in the comparison group and the relative effect of the intervention (and its $95 \% \mathrm{Cl}$ ).

CI: Confidence interval; RR: Risk ratio

GRADE Working Group grades of evidence

High certainty: We are very confident that the true effect lies close to that of the estimate of the effect

Moderate certainty: We are moderately confident in the effect estimate: The true effect is likely to be close to the estimate of the effect, but there is a possibility that it is substantially different

Low certainty: Our confidence in the effect estimate is limited: The true effect may be substantially different from the estimate of the effect

Very low certainty: We have very little confidence in the effect estimate: The true effect is likely to be substantially different from the estimate of effect

\section{Explanations}

a. Downgrade to imprecision because $\mathrm{Cl} 95 \%$ for absolute effects inclsuded clinically important benefit and no benefit. In addition, the sample size was small and did not reach $\mathrm{Cl} 95 \%$.

b. Downgrade to publication bias due to external financial benefit and relatively short follow-up period.

Figure 10 Summary of findings for the comparison of adalimumab versus placebo. Outcome: Satisfactory response to treatment.

Summary of findings:

\begin{tabular}{|c|c|c|c|c|c|c|}
\hline \multicolumn{7}{|c|}{ Adalimumab compared to Placebo for Child } \\
\hline \multicolumn{7}{|c|}{$\begin{array}{l}\text { Patient or population: Children with non-infectious uveitis } \\
\text { Setting: Population based in communities in France and UK } \\
\text { Intervention: Adalimumab } \\
\text { Comparison: Placebo }\end{array}$} \\
\hline \multirow{2}{*}{ Outcomes } & \multicolumn{2}{|c|}{$\begin{array}{l}\text { Anticipated absolute effects* } \\
\qquad(95 \% \mathrm{Cl})\end{array}$} & \multirow{2}{*}{$\begin{array}{l}\text { Relative effect } \\
(95 \% \mathrm{Cl})\end{array}$} & \multirow{2}{*}{$\begin{array}{l}\text { № of } \\
\text { participants } \\
\text { (studies) }\end{array}$} & \multirow{2}{*}{$\begin{array}{l}\text { Certainty of } \\
\text { the evidence } \\
\text { (GRADE) }\end{array}$} & \multirow{2}{*}{ Comments } \\
\hline & $\begin{array}{l}\text { Risk with } \\
\text { Placebo }\end{array}$ & $\begin{array}{l}\text { Risk with } \\
\text { Adalimumab }\end{array}$ & & & & \\
\hline $\begin{array}{c}\text { Reduction or } \\
\text { Discontinuation of } \\
\text { the Use of Systemic } \\
\text { or Topical } \\
\text { Corticosteroids }\end{array}$ & 167 per 1.000 & $\begin{array}{l}378 \text { per } 1.000 \\
(172 \text { to } 832)\end{array}$ & $\begin{array}{l}\text { RR } 2.27 \\
\text { (1.03 to } 4.99)\end{array}$ & $\begin{array}{l}102 \\
\text { (2 RCTs) }\end{array}$ & $\underset{\mathrm{LOW}}{\oplus \mathrm{CW}^{\mathrm{b}} \mathrm{O}}$ & \\
\hline \multicolumn{7}{|c|}{$\begin{array}{l}\text { *The risk in the intervention group (and its } 95 \% \text { confidence interval) is based on the assumed risk in the comparison group and the relative } \\
\text { effect of the intervention (and its } 95 \% \mathrm{Cl} \text { ). }\end{array}$} \\
\hline \multicolumn{7}{|c|}{ CI: Confidence interval; RR: Risk ratio } \\
\hline \multicolumn{7}{|c|}{$\begin{array}{l}\text { GRADE Working Group grades of evidence } \\
\text { High certainty: We are very confident that the true effect lies close to that of the estimate of the effect } \\
\text { Moderate certainty: We are moderately confident in the effect estimate: The true effect is likely to be close to the estimate of the effect, but there } \\
\text { is a possibility that it is substantially different } \\
\text { Low certainty: Our confidence in the effect estimate is limited: The true effect may be substantially different from the estimate of the effect } \\
\text { Very low certainty: We have very little confidence in the effect estimate: The true effect is likely to be substantially different from the estimate of } \\
\text { effect }\end{array}$} \\
\hline
\end{tabular}

\section{Explanations}

a. Downgrade to imprecision because $\mathrm{Cl} 95 \%$ for absolute effects inclsuded clinically important benefit and no benefit. In addition, the sample size was small and did not reach $\mathrm{Cl} 95 \%$.

b. Downgrade to publication bias due to external financial benefit and relatively short follow-up period.

Figure I I Summary of findings for the comparison of adalimumab versus placebo. Outcome: Reduction or discontinuation of corticosteroids use. 
Summary of findings:

\begin{tabular}{|c|c|c|c|c|c|c|}
\hline \multicolumn{7}{|c|}{ Adalimumab compared to Infliximab in Children with non-infectious uveitis } \\
\hline \multicolumn{7}{|c|}{$\begin{array}{l}\text { Patient or population: Children with non-infectious uveitis } \\
\text { Setting: Population based in communities in Italy, Russia and Turkey } \\
\text { Intervention: Adalimumab } \\
\text { Comparison: Infliximab }\end{array}$} \\
\hline Outcomes & \multicolumn{2}{|c|}{$\begin{array}{l}\text { Anticipated absolute effects }{ }^{*} \\
\qquad(95 \% \mathrm{CI})\end{array}$} & $\begin{array}{l}\text { Relative effect } \\
\quad(95 \% \mathrm{Cl})\end{array}$ & $\begin{array}{l}\text { № of } \\
\text { participants } \\
\text { (studies) }\end{array}$ & $\begin{array}{l}\text { Certainty of } \\
\text { the evidence } \\
\text { (GRADE) }\end{array}$ & Comments \\
\hline $\begin{array}{l}\text { Satisfactory } \\
\text { Response to } \\
\text { Treatment }\end{array}$ & 469 per 1.000 & $\begin{array}{c}\mathbf{5 5 3} \text { per } \mathbf{1 . 0 0 0} \\
(323 \text { to } 951)\end{array}$ & $\begin{array}{c}\mathbf{R R} \mathbf{1 . 1 8} \\
(0.69 \text { to } 2.03)\end{array}$ & $\begin{array}{l}342 \\
(5 \text { observational } \\
\text { studies) }\end{array}$ & $\begin{array}{l}\bigoplus \text { VERY LOW } \\
\underset{a, b, c}{ }\end{array}$ & \\
\hline
\end{tabular}

*The risk in the intervention group (and its $95 \%$ confidence interval) is based on the assumed risk in the comparison group and the relative effect of the intervention (and its $95 \% \mathrm{Cl}$ ).

CI: Confidence interval; RR: Risk ratio

\section{GRADE Working Group grades of evidence}

High certainty: We are very confident that the true effect lies close to that of the estimate of the effect

Moderate certainty: We are moderately confident in the effect estimate: The true effect is likely to be close to the estimate of the effect, but there is a possibility that it is substantially different

Low certainty: Our confidence in the effect estimate is limited: The true effect may be substantially different from the estimate of the effect

Very low certainty: We have very little confidence in the effect estimate: The true effect is likely to be substantially different from the estimate of effect

\section{Explanations}

a. Downgrade to global risk of bias because there was no randomization, allocation strategy, concealment of allocation and masking of participants, researchers and outcome evaluators.

b. Downgrade to inconsistency because $12=91 \%$.

c. Downgrade to imprecision because $\mathrm{Cl} 95 \%$ for absolute effects inclsuded clinically important benefit and no benefit. In addition, the sample size was small and did not reach $\mathrm{Cl} 95 \%$.

Figure 12 Summary of findings for the comparison of adalimumab versus infliximab. Outcome: Satisfactory response to treatment.

\section{Summary of findings:}

\section{Adalimumab compared to Inflix imab for Children with non-infectious uveitis}

Patient or population: Children with non-infectious uveitis

Setting: Population based in communities in Italy and Turkey

Intervention: Adalimumab

Comparison: Infliximab

\begin{tabular}{|c|c|c|c|c|c|c|}
\hline \multirow{2}{*}{ Outcomes } & \multicolumn{2}{|c|}{$\begin{array}{l}\text { Anticipated absolute effects* } \\
\qquad(95 \% \mathrm{Cl})\end{array}$} & \multirow{2}{*}{$\begin{array}{l}\text { Relative effect } \\
\qquad(95 \% \mathrm{CI})\end{array}$} & \multirow{2}{*}{$\begin{array}{l}\text { № of } \\
\text { participants } \\
\text { (studies) }\end{array}$} & \multirow{2}{*}{$\begin{array}{l}\text { Certainty of } \\
\text { the evidence } \\
\text { (GRADE) }\end{array}$} & \multirow{2}{*}{ Comments } \\
\hline & $\begin{array}{l}\text { Risk with } \\
\text { Infliximab }\end{array}$ & $\begin{array}{c}\text { Risk with } \\
\text { Adalimumab }\end{array}$ & & & & \\
\hline Adverse Event Rate & 168 per 1.000 & $\begin{array}{l}141 \text { per } 1.000 \\
(69 \text { to } 291)\end{array}$ & $\begin{array}{c}\mathbf{R R} \mathbf{0 . 8 4} \\
(0.41 \text { to } 1.73)\end{array}$ & $\begin{array}{c}279 \\
\text { (4 observational } \\
\text { studies) }\end{array}$ & $\underset{\text { LOW }^{a, b}}{\oplus}$ & \\
\hline
\end{tabular}

*The risk in the intervention group (and its $95 \%$ confidence interval) is based on the assumed risk in the comparison group and the relative effect of the intervention (and its $95 \% \mathrm{Cl}$ ).

CI: Confidence interval; RR: Risk ratio

GRADE Working Group grades of evidence

High certainty: We are very confident that the true effect lies close to that of the estimate of the effect

Moderate certainty: We are moderately confident in the effect estimate: The true effect is likely to be close to the es timate of the effect, but there is a possibility that it is substantially different

Low certainty: Our confidence in the effect estimate is limited: The true effect may be substantially different from the estimate of the effect

Very low certainty: We have very little confidence in the effect estimate: The true effect is likely to be substantially different from the estimate of effect

\section{Explanations}

a. Downgrade to global risk of bias because there was no randomization, allocation strategy, concealment of allocation and masking of participants, researchers and outcome evaluators.

b. Downgrade to imprecision because $\mathrm{Cl} 95 \%$ for absolute effects inclsuded clinically important benefit and no benefit. In addition, the sample size was small and did not reach $\mathrm{Cl} 95 \%$.

Figure 13 Summary of findings for the comparison of adalimumab versus infliximab. Outcome: Local and systemic adverse events. 
these agents in pediatric uveitis. Although equality of evidence still indicates the need for more randomized studies to increase the strength of the recommendation, biological therapy is consolidating itself as a viable option in the treatment of noninfectious pediatric uveitis.

\section{Strengths and Limitations}

The review has several strengths, including extensive, sensitive, and critical literature research, with no language restrictions or publication status. The analysis of the strength of the evidence through the GRADE system ${ }^{15,16}$ and risk of bias of NRS through the ROBINS-I tool ${ }^{14}$ were also differential.

The main limitations were the reduced number of included studies, the moderate risk of bias of NRS, and the high heterogeneity observed in a meta-analysis with NRS (91\%).

The certainty of evidence of the outcomes ranged from very low to low. Classification downgrading occurred mainly because of methodological flaws in NRS, imprecision, heterogeneity, and publication bias.

\section{Conclusion}

In conclusion, there is evidence that anti-TNF $\alpha$ drugs are viable therapeutic options in clinical practice and are effective in controlling inflammation and reducing corticosteroid therapy in noninfectious refractory pediatric uveitis to standard treatment. The evidence for the similar efficacy of adalimumab and infliximab lacks solid evidence since the existing ones were generated from NRS. More RCTs are still needed, comparing the various anti$\mathrm{TNF} \alpha$ drugs available, with methodological quality, standardized outcomes, and adequate sample size to confirm and increase the certainty of evidence found in this review.

\section{Disclosure}

None of the authors has any potential conflict of interest to disclose.

\section{References}

1. Gamalero L, Simonini G, Ferrara G, Polizzi S, Giani T, Cimaz R. Evidence-based treatment for uveitis. Isr Med Assoc J. 2019;21 (7):475-479.

2. Siiskonen M, Hirn I, Pesälä R, Hautala T, Ohtonen P, Hautala N. Prevalence, incidence and epidemiology of childhood uveitis. Acta Ophthalmol. 2021;99(2):e160-e163. doi:10.1111/aos.14535

3. Chan NS, Choi J, Cheung CMG. Pediatric Uveitis. Asia Pac J Ophthalmol. 2018;7(3):192-199.

4. Thurau S. Childhood Uveitis. Klin Monbl Augenheilkd. 2020;237 (10):1177-1186. doi:10.1055/a-1252-5281.
5. Cann M, Ramanan AV, Crawford A, et al. Outcomes of noninfectious Paediatric uveitis in the era of biologic therapy. Pediatr Rheumatol Online J. 2018;16(1):51. doi:10.1186/s12969-018-0266-5

6. Barut K, Adrovic A, Şahin S, Kasapçopur Ö. Juvenile Idiopathic Arthritis. Med J. 2017;34(2):90-101.

7. Thomas AS. Biologics for the treatment of noninfectious uveitis: current concepts and emerging therapeutics. Curr Opin Ophthalmol. 2019;30(3):138-150. doi:10.1097/ICU.0000000000000562

8. Heiligenhaus A, Ninhes T, Schumacher C, et al. Diagnostik und antientzündliche Therapie der Uveitis bei juveniler idiopathischer Arthritis. In: Wirth S, Creutzig R, Krauspe R, Lehrnbecher T, Mentzel HJ, Niehues $\mathrm{T}$, editors. Leitlinien Kinder- und Jugendmedizin. Urban \& Fischer; 2015. H8.1-H8.17.

9. Phatak S, Agrawal R, Pavesio C. Adalimumab: viable treatment option for pediatric refractory uveitis? Expert Rev Ophthalmol. 2014;9(3):175-184. doi:10.1586/17469899.2014.903801

10. Tugal-Tutkun I, Ayranci O, Kasapcopur O, Kir N. Retrospective analysis of children with uveitis treated with infliximab. $J$ AAPOS. 2008;12(6):611-613. doi:10.1016/j.jaapos.2008.08.007

11. Hu Y, Huang Z, Yang S, Chen X, Su W, Liang D. Effectiveness and Safety of Anti-Tumor Necrosis Factor-Alpha Agents Treatment in Behcets' Disease-Associated Uveitis: a Systematic Review and MetaAnalysis. Front Pharmacol. 2020;11:941. doi:10.3389/fphar.2020.00 941

12. Higgins JPT, Thomas J, Chandler J, et al. Cochrane Handbook for Systematic Reviews of Interventions. 2th ed. Chichester (UK): John Wiley \& Sons; 2019.

13. Moher D, Liberati A, Tetzlaff J, Altman DG; PRISMA Group. Preferred reporting items for systematic reviews and meta-analyses: the PRISMA statement. BMJ. 2009;339:b2535. doi:10.1136/bmj. b2535

14. Sterne JA, Hernán MA, Reeves BC, et al. ROBINS-I: a tool for assessing risk of bias in non-randomised studies of interventions. BMJ. 2016;355:i4919. doi:10.1136/bmj.i4919

15. Guyatt GH, Oxman AD, Vist GE, et al. GRADE: an emerging consensus on rating quality of evidence and strength of recommendations. BMJ. 2008;336(7650):924-926. doi:10.1136/ bmj.39489.470347.AD

16. Guyatt G, Oxman AD, Akl EA, et al. GRADE guidelines: 1. Introduction-GRADE evidence profiles and summary of findings tables. J Clin Epidemiol. 2011;64(4):383-394. doi:10.1016/j.jclinepi. 2010.04.026

17. McMaster University. GRADEpro GDT: gRADEpro Guideline Development Tool [Software] [Internet]. Evidence Prime, Inc.; 2015. Available from: https://gradepro.org. Accessed August 30, 2021.

18. The Cochrane Collaboration. Review Manager (Revman). Copenhagen: The Nordic Cochrane Centre; 2015.

19. Smith JA, Thompson DJS, Whitcup SM, et al. A randomized, placebo-controlled, double-masked clinical trial of etanercept for the treatment of uveitis associated with juvenile idiopathic arthritis. Arthritis Rheum. 2005;53:18-23. doi:10.1002/art.20904

20. Quartier P, Baptiste A, Despert V, et al. ADJUVITE: a double-blind, randomised, placebo-controlled trial of adalimumab in early-onset, chronic, juvenile idiopathic arthritis-associated anterior uveitis. Ann Rheum Dis. 2017;77:1-9.

21. Ramanan AV, Dick AD, Jones AP, et al. Adalimumab plus Methotrexate for Uveitis in Juvenile Idiopathic Arthritis. N Engl $J$ Med. 2017;376(17):1637-1646. doi:10.1056/NEJMoa1614160

22. Tynjälä P, Lindahl P, Honkanen V, Lahdenne P, Kotaniemi K. Infliximab and etanercept in the treatment of chronic uveitis associated with refractory juvenile idiopathic arthritis. Ann Rheum Dis. 2007;66(4):548-550. doi:10.1136/ard.2006.058248

23. Simonini G, Taddio A, Cattalini M, et al. Prevention of flare recurrences in childhood-refractory chronic uveitis: an open-label comparative study of adalimumab versus infliximab. Arthritis Care Res. 2011;63:612-618. doi:10.1002/acr.20404 
24. Zannin ME, Birolo C, Gerloni VM, et al. safety and efficacy of infliximab and adalimumab for refractory uveitis in juvenile idiopathic arthritis: 1-year follow-up data from the Italian Registry. J Rheumatol. 2013;40(1):74-79. doi:10.3899/jrheum.120583

25. Gaidar EV, Kostik MM, Snegireva LS, et al. Outcomes of treatment of juvenile idiopathic arthritis related uveitis with TNF-alpha inhibitors. Pediatrician. 2014;5:60-64.

26. Cecchin V, Zannin ME, Ferrari D, et al. Long-term Safety and Efficacy of Adalimumab and Infliximab for Uveitis Associated with Juvenile Idiopathic Arthritis. J Rheumatol. 2018;45(8):1167-1172. doi:10.3899/jrheum.171006

27. Gunduz GU, Yalcinbayir O, Cekic S, Yildiz M, Kilic SS. Anti-Tumor Necrosis Factor Treatment in the Management of Pediatric Noninfectious Uveitis: infliximab Versus Adalimumab. $J$ Ocul Pharmacol Ther. 2021;37:1-5.

28. Schnabel A, Unger E, Brück N, et al. High-dose intravenous methylprednisolone in juvenile noninfectious uveitis: a retrospective analysis. Clin Immunol. 2019;211:108327. doi:10.1016/j.clim.2019.108327

29. Gallego-Pinazo R, Dolz-Marco R, Martínez-Castillo S, Arévalo JF, Díaz-Llopis M. Update on the principles and novel local and systemic therapies for the treatment of non-infectious uveitis. Inflamm Allergy Drug Targets. 2013;12(1):38-45. doi:10.2174/1871528111312010006
30. Heiligenhaus A, Mingels A, Heinz C, Ganser G. Methotrexate for uveitis associated with juvenile idiopathic arthritis: value and requirement for additional anti-inflammatory medication. Eur J Ophthalmol. 2007;17(5):743-748. doi:10.1177/112067210701700 509

31. Hughes DA, Culeddu G, Plumpton CO, et al. Cost-Effectiveness Analysis of Adalimumab for the Treatment of Uveitis Associated with Juvenile Idiopathic Arthritis. Ophthalmology. 2019;126 (3):415-424. doi:10.1016/j.ophtha.2018.09.043

32. Lightman S, Niederer R, Sharma S, et al. Cost-effectiveness analysis of adalimumab for the treatment of uveitis associated with juvenile idiopathic arthritis. Ophthalmology. 2019;126(3):e22-e24. doi:10.10 16/j.ophtha.2018.12.004

33. Symes RJ, Zagora SL, Younan C, et al. Cost-effectiveness analysis of adalimumab for the treatment of uveitis associated with juvenile idiopathic arthritis. Ophthalmology. 2019;126(10):e77. doi:10.1016/ j.ophtha.2019.04.039

34. Simonini G, Druce K, Cimaz R, Macfarlane GJ, Jones GT. Current Evidence of Anti-Tumor Necrosis Factor $\alpha$ Treatment Efficacy in Childhood Chronic Uveitis: a Systematic Review and Meta-Analysis Approach of Individual Drugs. Arthritis Care Res (Hoboken). 2014;66(7):1073-1084. doi:10.1002/acr.22214
Clinical Ophthalmology

\section{Publish your work in this journal}

Clinical Ophthalmology is an international, peer-reviewed journal covering all subspecialties within ophthalmology. Key topics include: Optometry; Visual science; Pharmacology and drug therapy in eye diseases; Basic Sciences; Primary and Secondary eye care; Patient Safety and Quality of Care Improvements. This journal is indexed on PubMed

\section{Dovepress}

Central and CAS, and is the official journal of The Society of Clinical Ophthalmology (SCO). The manuscript management system is completely online and includes a very quick and fair peer-review system, which is all easy to use. Visit http://www.dovepress.com/ testimonials.php to read real quotes from published authors. 